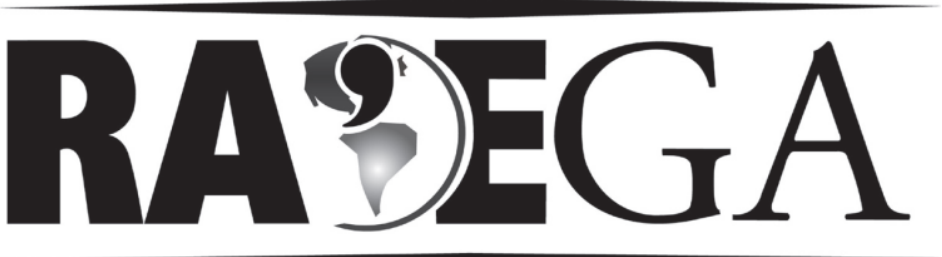

O ESPAÇO GEOGRÁFICO EM ANÁLISE

\title{
GEOGRAFIA E CULTURA \\ O ESPAÇO EM PROSA, MAPA LITERÁRIO E \\ IMAGINAÇÃO
}

\author{
GEOGRAPHY AND CULTURE \\ SPACE PROSE, LITERARY MAP AND IMAGINATION
}

\author{
Marquessuel Dantas de Souza ${ }^{1}$
}

\section{RESUMO}

Este pequeno esboço busca discutir brevemente a relação que envolve Geografia e Literatura, especificamente a poesia e o romance. Do mesmo modo, visa apontar a importância da temática quando da discussão referente ao espaço geográfico como o espaço de vivencia e de experiências dos autores e personagens poéticos, onde são articuladas as perspectivas fenomenológicas-existenciais dos mesmos. Bem como valorizar a prosa sobre o espaço, os mapas literários e a imaginação contida numa obra de arte significativamente na cultura dos homens.

Palavras-chave: Geografia. Cultura. Arte. Literatura. Espaço.

\footnotetext{
${ }^{1}$ Graduado em Geografia. Faculdades Integradas Tereza Martin (FATEMA). São Paulo-SP, Brasil. marquessuelgf@gmail.com marquessuuelgf@yahoo.com.br
} 


\section{ABSTRACT}

This small sketch briefly discusses the relationship that involves geography and literature, specifically poetry and romance. Similarly, aims to highlight the importance of theme in the discussion regarding the geographical space as the space of experiences and experiences of the authors and poetic characters, which are articulated the existential-phenomenological perspectives of the same. And to capitalize on space prose, maps and literary imagination contained in a work of art culture of men significantly.

Keywords: Geography. Culture. Arts. Literature. Space.

\section{INTRODUÇÃO}

A Ciência Geográfica há muito vem trabalhando seu objeto de estudo sobre variadas formas de manifestação e representação. Não obstante, busca por relacionar os melhores olhares a serem direcionados sobre o espaço como a instância máxima de aproximação e distanciamento entre os seres existenciais. Bem entendido, essas formas de manifestação no espaço irá se efetuar na superfície da terra por intermédio de representações humanas evidenciando-se a dialética corporal à priori, visto que "o corpo do poeta se completa com o poema" (MARINHO, 2010, p. 96). Entretanto, sem para isso, deixar escapar de seu cerne os lugares posicionados na memória do artista.

Em nosso caso, a linguagem literária aqui é privilegiada, por conseguinte, "os testemunhos fornecidos por gravuras e pinturas" (BARCELLOS, 2009, p. 42) também são de suma importância. No entanto, nossa discussão se volta para a análise de escritos literários, tais como poemas e romances. Pois "somos aquilo que vivemos" (SOUZA, 2012, p. 84). Por conseguinte, a poesia é uma alma inaugurando uma forma (JOUVE, citado por BACHELARD, 1965, $p$. 14). E, "através da arte [...] nos transcendemos" (SOUZA, 2012, p. 81). Não obstante, para além do comum "tudo é cultural em nós" (MELEAU-PONTY, 2007, p. 229). 


\title{
GEOGRAFIA, LITERATURA E ARTE
}

A dialética entre Geografia e Literatura é fundamental para compreendermos a relação do ser ou criador artístico com a experiência da narrativa dos lugares.

\begin{abstract}
Os estudos geográficos realizados a partir da análise de textos literários já constituem uma linha de pesquisa consolidada na geografia internacional. No entanto, tal tema é pouco privilegiado na geografia brasileira, a despeito da riqueza que apresenta a produção literária. Na relação entre Geografia e Literatura, os textos literários apresentam-se como um rico material a ser apreciado por nós geógrafos, pois eles evocam a alma dos lugares e o cotidiano das pessoas (BARCELLOS, 2009, p. 41).
\end{abstract}

Portanto, devemos enfatizar o papel da arte (Literatura, Pintura, Música, Cinema e etc.) como um todo, nas discussões de cunho geográfico. Isso para valorizar a cultura como o bem maior de um grupo humano. Pois, "através da arte o homem mostra sua expressão criadora, realizando assim, uma capacidade intrínseca do ser-espacial, de sua subjetividade com sua objetividade com e no mundo" (SOUZA, 2012, p. 73-74).

\begin{abstract}
Muito embora um poeta seja um tecelão, pois o mesmo vai tecendo as palavras que surgem, e assim compondo seus versos, a poesia o envolve de tal modo que por intermédio de um simples poema, o autor não raro, procura advogar aquilo que não conseguiria expressar de outra maneira. E é através da arte que o homem procura embelezar o mundo no qual está inserido. Tanto quanto faz com sua higiene pessoal (SOUZA, 2012, p. 74).
\end{abstract}

"A Geografia, que hoje procura novas alternativas para formas de apreensão do espaço, muito tem a ganhar através da incorporação crítica de discursos como o da literatura, os quais podem servir como recurso de renovação metodológica para o ensino desta disciplina" (BARCELLOS, 2009, p. 42). Pois que, em particular, "o espaço pode apresentar-se como componente principal da narrativa sendo fundamental, quando não determinante, no desenvolvimento da ação. No entanto, a geografia brasileira tem se privado de participar deste debate, a despeito da riqueza espacial que 
apresenta sua produção literária” (DIMAS, citado por BARCELLOS, 2009, p. 42).

No entanto, "o interesse pela temática geografia e literatura" (BARCELLOS, 2009, p. 42) é algo que cada vez mais está ocupando horizontes na Geografia Cultural, principalmente em relação ao debate sobre a "representação do espaço e dos lugares" (BARCELLOS, 2009, p. 42). Haja vista que, "dentro deste contexto a literatura moderna deixou de ter como tema central, entre os geógrafos, o meio ambiente e passou a dar uma maior relevância ao lugar e seus significados e à relação entre as pessoas e o lugar como nos aponta Pocock" (Idem, 2009, p. 42). Assim sendo, "dessa forma, a literatura não somente reconstitui uma experiência, como também formula experiências" (BARCELLOS, 2009, p. 42). Isto é, a Literatura expressa experiência. De um modo geral, a poesia completa o autor. Logo, "falamos do poeta, figura que, muitas vezes, desagradada com a realidade humana, a vive, tirando do seu contexto a matéria de sua criação: a poesia” (MARINHO, 2010, p. 85). Todavia, "a sua criação artística não se confunde com o lugar, mas tira deste os germes que propiciam a sua configuração" (Idem, 2010, p. 85). A poesia é elaborada "a partir do contexto objetivo com o qual o homem situado se defronta" (Idem, 2010, p. 86).

Bem entendido, "é por intermédio da poesia que o poeta vive e expressa de maneira singular sua vida. De todo modo, o mesmo extrai de si aquilo que está depositado no seu ser, ser este, existencial" (SOUZA, 2012, p. 76). Essa extração é aquilo que se encontra na profundeza de seu interior. Nessa relação "o artista atribui significados ao mundo por meio de sua obra" (ARANHA; MARTINS, 1986, p. 385). É assim que "o artista põe sua marca” (MERLEAUPONTY, 2002, p. 104) no mundo, seja por meio da pintura, do romance, do poema, da música, do conto ou de outra arte qualquer. Porém, sempre buscando expressar suas experiências por meio de uma linguagem específica: a arte. 
Nosso objetivo é relacionar Geografia e Literatura e mostrar a importância dessa aproximação ou, interdisciplinaridade que as envolvem. Para isso a fenomenologia como metodologia ocupa um lugar privilegiado nesta abordagem. Pois em particular a visão fenomenológica remete ao sujeito uma maior compreensão dos sentidos, dos valores e dos estudos que o envolve como um todo no mundo. Contudo, deve-se considerar uma boa parte desses estudos à análise psicológica desses sujeitos, ou seja, considerar a produção artística dos mesmos por meio da memória.

A nova perspectiva na Geografia ainda deixa a desejar sobre a temática. Para tanto, inferimos que "o objeto de estudo geográfico deveria dar uma importância maior ao lugar e à relação que os indivíduos estabelecem com ele" (BARCELLOS, 2009, p. 43). Bem entendido, a literatura como estudo geográfico possibilita a "transcrição da experiência dos lugares" (BARCELLOS, 2009 , p. 32) para com seus habitantes. Sendo assim, em relação à literatura, isto tem como resultado a percepção do lugar ou dos lugares apreendidos por quem os vivencia efetivamente. Neste contexto, o romance assim como o poema "é visto como o encontro entre o mundo objetivo e a subjetividade humana" (BARCELLOS, 2009, p. 43). Isto quer dizer que o romance e o poema dariam "conta não apenas dos aspectos objetivos da realidade, mas também de sua subjetividade" (BARCELLOS, 2009, p. 42). Em todo caso inferimos de certo que a "arte é subjetivação objetivada" (SOUZA, 2012, 68-69).

Não obstante, o diálogo presente nas obras literárias é significante para a compreensão geográfica de tais obras. Pois, conforme nos aponta Barcellos, sua orientação é que Marc Brosseau nos fornece uma importante contribuição aos estudos geográficos sobre textos literários quando nos "diz respeito à proposição do método dialógico" (BARCELLOS, 2009, p. 43). Não obstante, "o diálogo aparece como uma opção plausível do romance, sendo uma possibilidade de comunição entre Geografia e Literatura enquanto campos autônomos do conhecimento" (BARCELLOS, 2009, p. 43-44). Neste sentido, "os textos literários, portanto, não podem ser reduzidos a uma mera 
incorporação de mitos e articulações de ideologias, eles soam muito mais que isso, pois nos comunicamos através deles" (BARCELLOS, 2009, p. 44).

A Arte como um todo nos transmite significações e valores humanos profundos. "A arte não isola" (COLI, 1985, p. 110), pois esta é "um elemento da vida" (MÁRIO de ANDRADE, citado por COLI, 1985, p. 87). Portanto, a arte nos acompanha e nos faz aproximar do eu interior. "A arte é, assim, objetivação da criatividade humana diante de si e do seu próprio mundo significado. É a totalização de si, permanentemente se fazendo" (MARINHO, 2010, pp. 82-83). Por conseguinte, "a obra de arte é simplesmente um meio de facilitação do conhecimento da Ideia" (SCHOPENHAUER, 2005, p. 265).

\begin{abstract}
A poesia, ela, é uma forma particular de arte que se anuncia enquanto solo criativo do ser-espacial e que se pretende unificadora do corpo e do pensamento. Ela estabelece a tensão unificadora inscrevendo o homem no mundo e mediando o que há de afirmativo e de negativo nessa presença. A poesia, forma de objetivação específica do ser-espacial, afora alguns interstícios especulativos, surge, antes de tudo, da relação do homem situado com o lugar, o espaço de existência (MARINHO, 2010, p. 84).
\end{abstract}

Com efeito, "a realização poética é meio para que o indivíduo torne real a sua passagem do singular contido em si para o universal contido na realidade vivida, com a qual o mesmo se relaciona" (MARINHO, 2010, p. 213). Não obstante, "a escrita poética tem a ver com o sentido de resgatar a subjetividade e pô-la à mostra no contorno real da vida humana" (MARINHO, 2010, p. 219). $\mathrm{O}$ ato de escrever torna possível testemunhar "que aqui estivemos e assim fomos" (EDUARDO GALEANO apud in MARINHO, 2010, p. 220).

\title{
UMA PROSA SOBRE O ESPAÇO, OS MAPAS LITERÁRIOS E A IMAGINAÇÃO
}

As noções de espaço contidos na reflexão entre Geografia e Literatura se apresentam enraizadas no contexto de cada obra. Deste modo, além da 
própria discussão que envolve o espaço geográfico - como a superfície da terra -, a reflexão citada nos oferece meios para discutirmos o espaço fictício presente em tais obras de arte. Por sua vez, há "espaços que expressam muito mais do que a manifestação concreta" (BARCELLOS, 2009, p. 46) da materialidade, tais como prédios, estradas, ruas, montanhas, rios e etc. Em outras palavras, "há espaços a partir dos quais se cria uma leitura simbólica, que pode ser sagrada, poética ou simplesmente folclórica, capaz de fortalecer uma identidade coletiva e também territorial, conforme nos aponta Haesbaert" (BARCELLOS, 2009, p. 46). Entrementes, para que isso se realize evidenciase a importância do imaginário, sem antes negar a materialidade da existência concreta.

"É a imaginação que metamorforseia a comunidade humana e o ambiente natural em uma significativa unidade de espaço" (COSGROVE, citado por BARCELLOS, 2009, p. 46). Por conseguinte, "fazendo da comunicação o alicerce da subjetividade" (BARCELLOS, 2009, p. 46) inerente ao sujeito humano. Contudo, "toda arte consiste em comunicação" (MARINHO, 2010, p. 51). Por isso "o poeta tem por tarefa, definitivamente, traduzir" (MERLEAUPONTY, 2002, p. 90) palavras, vozes, e acentos "cujo eco cada coisa ou cada circunstância Ihe envia” (MERLEAU-PONTY, 2002, p. 91). Portanto, é dessa comunicação que surge a criação artística.

\begin{abstract}
A apreensão do espaço geográfico pela via do discurso literário do romance busca uma imbricação entre o real e o imaginário, entre o objetivo e o subjetivo, a qual nos fornece um entendimento do discurso literário como forma de representação do espaço real (BARCELLOS, 2009, p. 46).
\end{abstract}

Isso também é válido no caso do poema. Do mesmo modo, vale para a arte pictórica, para a música e para o cinema. Neste sentido, o imaginário ganha terreno consubstancialmente. E é assim que "o artista nos permite olhar para o mundo mediante os seus olhos" (SCHOPENHAUER, 2005, p. 265). Em realidade, é através da arte que conhecemos outro mundo no qual não saberíamos expressar nossas ideias se não por meio desta. Deste modo, como 
nos reporta Schopenhauer: "o poeta é o espelho da humanidade" (SCHOPENHAUER, 2005, p. 329). Este nos faz ver a nossa imagem diante nossa própria existência concreta.

"Os textos literários não só podem como devem ser utilizados como um rico material a ser interpretados sobre as várias representações do espaço" (BARCELLOS, 2009, p. 51). Em particular o espaço geográfico.

\begin{abstract}
A geografia literária pode se referir a duas coisas muito diferentes: o espaço na literatura que é ficcional e a literatura no espaço que é o espaço histórico real. A distinção entre os dois espaços não afeta o método de pesquisa, que é o mesmo em toda parte e se baseia no uso sistemático de mapas. De mapas não como metáforas, mas como ferramentas analíticas que dissecam o texto de uma forma incomum, trazendo à luz relações que de outro modo ficariam ocultas. Os mapas literários nos permitem ver a natureza espacial das formas literárias (suas fronteiras e rotas favoritas) e também trazem à luz a lógica em torno do qual um enredo se aglutina e se organiza (MORETTI, citado por BARCELLOS, 2009, p. 47).
\end{abstract}

Bem entendido, quando buscamos a geograficidade num poema ou num romance, podemos mapear os espaços e os lugares contidos nos mesmos. Do mesmo modo, podemos nos localizar no tempo. Pois, "ao analisar os romances, Moretti enfatiza a relação dos mesmos com o tempo, não deixando de sugerir que o componente espacial é tão notável quanto o temporal" (BARCELLOS, 2009, p. 47). Haja vista o tempo e o espaço não se separarem no contexto literário, pois são instâncias existenciais do ser no mundo. Em nosso entender, é "geografizando um poema, por exemplo, que encontramos a ideia de pertencimento, de identidade, tanto por parte dos personagens contidos no poema quanto do autor, escritor de tal poema" (SOUZA, 2012, p. 69). O mesmo é válido para um romance ou para um conto.

Para uma melhor compreensão do que fora citado logo acima, "é buscando os conteúdos geográficos numa obra de arte, isto é, "geografizando", que encontraremos o elo entre Geografia e Literatura. A amálgama entre ambas ajuda-nos na compreensão da realidade. Tanto do pretérito quando do tempo presente. Nessa relação (Geografia e Literatura) podemos identificar 
como se dá o envolvimento do homem com a terra, em outros termos, como se dá o envolvimento do homem no espaço de existência” (SOUZA, 2012, p. 83). Em outras palavras, como se mescla a cultura dos povos em geral.

\begin{abstract}
No processo onto-geográfico (geograficidade, espaço de existência, vida, etc.), sou participante do mundo, bem como vítima do mesmo. $\mathrm{E}$, com efeito, denuncio e anuncio, através da arte (no caso, a poesia) um mundo que estava recalcado em mim. É das camadas mais profundas de nosso ser, em conflitos com a geograficidade, que surge a subjetivação-objetivada, a saber - a arte. E é nesse relacionamento que atingimos o ultrapassamento do eu interior para o eu exterior, através da criação artística, extraordinariamente. E, grosso modo, através desse processo efetuamos simplesmente introspecção, bem como refletimos metafisicamente (SOUZA, 2012, p. 82-83).
\end{abstract}

Diante o exposto, lugar e espaço se imbricam reciprocamente. Para Tuan "o lugar é uma pausa em movimento" (TUAN, citado por NOGUEIRA, 2001, pp. 48-49). Neste sentido, o espaço é entendido como o movimento, "aberto, livre, amplo, vulnerável provocando medo, ansiedade, desprezo, sendo desprovido de valores e de qualquer ligação afetiva. Já o lugar é fechado, íntimo, humanizado" (MELLO, citado por NOGUEIRA, 2001, p. 49). Não obstante, o lugar seria "o espaço singular" (SILVA, 1986, p. 99). O lugar entendido aqui como "território demarcado, personalizado, possuidor de uma aura que atrai ou repele, mas envolve, protege, resguardando as vivências e as experiências da vida, criando ambiências, sendo pausas em movimentos maiores" (LIMA, citado por NOGUEIRA, 2001, p. 49). Por conseguinte, "espaço é mais abstrato que do que lugar" (TUAN, 1983, 06), ou melhor, "o espaço é abstrato e o lugar é concreto" (TUAN, 2011, p. 17). "O espaço é pois o maior lugar possível" (SILVA, 1978, p. 07) "e o lugar é o menor espaço possível" (SILVA, citado por NOGUEIRA, 2001, p. 50). Com efeito, a relação envolvendo espaço e lugar nos permite salientar a importância de analisar o lugar como o mais íntimo frente a nossa discussão. Em todo caso, "o lugar torna-se realidade a partir de nossa familiaridade com o espaço, não necessitando ser definido através de uma imagem precisa, limitada. Quando o espaço nos é inteiramente familiar, tornase lugar" (BARCELLOS, 2009, p. 48). Neste sentido "é elucidativo apontar de 
como os espaços, tais como ruas, praças e etc., a partir do momento que articulam vivencias e experiências, ao mesmo tempo em que passam a ser dotados de valor e sentimentos, tornam-se lugares" (BARCELLOS, 2009, $p$. 48).

\section{CONSIDERAÇÕES FINAIS}

Às várias possibilidades de se realizarem estudos que considerem a "literatura como importante forma de representação espacial" (BARCELLOS, 2009 , p. 50) deve ser considerada preponderantemente na Geografia, especificamente na Geografia Humanista Cultural, se assim quisermos contribuir efetivamente para com a Ciência Geográfica. Em particular a Geografia Humana Brasileira.

A fim de evidenciarmos nossa breve discussão sobre a questão que envolve Geografia e Literatura, observemos o diálogo de Merleau-Ponty em $A$ dúvida de Cézane quando este se expressa de maneira concisa: "O artista é aquele que fixa e torna acessível aos mais 'humanos' dos humanos o espetáculo de que fazem parte sem vê-lo" (MERLEAU-PONTY, 2004, p. 134). Em outros termos, a imagem oculta que permanece no interior do artista, o mesmo busca trazer à luz num espetáculo de transcendência viva que o permeia em toda sua existência real.

O mesmo autor ainda nos diz: "o artista põe sua marca" (MERLEAUPONTY, 2002, p. 104) no mundo através de sua obra, seja esta a pintura, o romance, o poema, o conto ou a música. Simplesmente temos um ser diferenciado vivendo entre muitos outros. Porém, este se destaca por sua capacidade e habilidade de conhecer além daquilo que está habituado. Este ser é o artista. Ele expressa seus sentimentos, suas experiências por meio de uma linguagem simbólica cheia de significados, chamada Arte.

Com efeito, "os textos literários não só podem como devem ser utilizados como um rico material a ser interpretados sobre as várias representações do 
espaço" (BARCELLOS, 2009, p. 51). Em particular o espaço geográfico. Como dito anteriormente. Isso é o que por ora compreendemos.

\section{REFERENCIAS BIBLIOGRÁFICAS}

ARANHA, Maria L. de Arruda e MARTINS, Maria H. Pires, Filosofando: introdução à filosofia. São Paulo: Ed. Moderna, 1986, p. 444.

BACHELARD, Gaston. La Poética del Espacio. México-Buenos Aires: Fondo de Cultura Econômica, 1965, p. 304.

BARCELLOS, Frederico Roza. Espaço, Lugar e Literatura: o olhar geográfico machadiano sobre a cidade do Rio de Janeiro. In: Espaço e Cultura. UERJNEPEC, RJ, n²5, pp. 41-52, Jan./Jun. de 2009.

COLI, Jorge. O que é Arte. 6ª Edição. São Paulo: Brasiliense, 1985, p. 136.

MARINHO, Samarone Carvalho. Um homem, um lugar: geografia da vida e perspectiva ontológica. 2010, 335. p. Tese de doutorado. Departamento de Geografia da USP. São Paulo.

MERLEAU-PONTY, Maurice. O Olho e o Espírito. São Paulo: Cosac \& Naify, 2004, p. 168.

O Visível e o Invisível. São Paulo: Perspectiva, 2007, p. 276.

A Prosa do Mundo. São Paulo: Cosac \& Naify, 2002, p. 192.

NOGUEIRA, Amélia Regina Batista. Percepção e Representação Gráfica: A "Geograficidade" nos Mapas Mentais dos Comandantes no Amazonas. 2001, p. 181. Tese de doutorado. Departamento de Geografia da USP. São Paulo.

SCHOPENHAUER, Artur. O Mundo como Vontade e Representação. São Paulo: Unesp. 2005, p. 696.

SILVA, Armando Correa da. O Espaço Fora do Lugar. São Paulo: Hucitec, 1978.

. De quem é o pedaço? Espaço e Cultura. São Paulo: Hucitec, 1986.

SOUZA, Marquessuel Dantas de. Geografia e Percepção: uma interpretação introdutória a partir da fenomenologia de Merleau-Ponty. São Paulo: Biblioteca 24 horas, 2012, p. 134. 
TUAN, Yi-Fu. Espaço e Lugar: a perspectiva da experiência. São Paulo: Difel, 1983, p. 251.

Espaço, Tempo, Lugar: um arcabouço humanista. In: Geograficidade. Niterói, v. 01, nº 01, Inverno, pp. 08-19, 2011. 